\title{
Conceptual model of portfolio management project for territories protection against flooding
}

\author{
Yuriy Starodub ${ }^{1}$, Andrii Havrys ${ }^{1, *}$ \\ ${ }^{1}$ Lviv State University of Life Safety, 79000, 35 Kleparivska St., Ukraine
}

\begin{abstract}
The actualization of portfolio management research is compounded by the intensive increase in the number of Emergency Service problems. The solution of this problem requires the application of a scientific approach to the adaptation of companies to rapid environmental changes [1]. In order to solve the problems of the service management, which at present exist in the State Emergency Service of Ukraine [2], the only solution is the introduction of a portfolio management into all organizational and managerial structures. According to the proposed model, the main goal of the global project is to form a portfolio of protection projects against flooding to ensure the safety of territories and the vital functions of the population on them. The model has the implementation of the phase updating territories protection projects from flooding based on the assessment of the overall indicator "level of danger of territories", which is intended to determine the priority for the implementation the portfolio of the territory's security. This method involves the selection of safety criteria and expert's assessments of the territory according to selected criteria. It is influenced by the strategy of the SESU for the regional strategy of development the administrative territories.
\end{abstract}

\section{Objectives and investigated problems}

According to the American Centre for Business Studies, portfolio management is at a very low level in the vast majority of companies, not to mention non-profit institutions [3]. After summing up, it turned out that about $90 \%$ of organizations are at Project Level 1 or 2 of the Project Portfolio Management (PPM) levels, and none have yet reached the 4 or 5 levels of portfolio maturity [3]. It is not surprising if we take into account the fact that more than $70 \%$ of organizations began to implement portfolio management projects only a few years ago [4]. At the same time, only $13 \%$ use special software tools for project portfolio management. However, despite the relatively low average level of PPM development, the vast majority of organizations (more than 90\%) consider this trend to be one of the key. Moreover, as research shows, large organizations are already aware of the need to implement PPM and more often use special software for this [5].

\footnotetext{
${ }^{*}$ Corresponding author: Havrys.AND@gmail.com
} 
The urgency of portfolio management research is compounded by the intensive increase in the number of problems, the solution of which requires the application of a scientific approach to the adaptation of companies to rapid environmental changes. Therefore, systematization and generalization of the scientific-theoretical and applied aspects of the implementation portfolio-oriented management are topical issues of the project management theory and practice.

In order to solve the problems of the management of the service, which at present exist in the state emergency service (SES) of Ukraine, the only solution is the introduction of a portfolio management into all organizational and managerial structures.

For state structures, the implementation of portfolio management practices has become quite relevant in the last 10 years, as the global development of this area and related special software does not allow them to remain on an equal footing with commercial organizations in similar fields without the introduction of a managerial-oriented approach.

Ensuring the security of the territories is a complex task that requires a portfoliooriented approach to implement all protection projects in the chosen territory. To carry out all independent projects, it is necessary to form an effective portfolio of projects of this territory, which we call the regional project portfolio. In addition, we need the effective management of this portfolio. Therefore, for the first we will analyze which groups of processes are managing of projects portfolio according to the international standard Project management institution (PMI) [6].

In order to effectively form and manage the portfolios of projects for protecting territories from flooding it is necessary to consider that: the performance of these portfolios is social, not commercial value. The portfolio of projects implemented on the territories is to be selected according to special criteria. To carry out the selection of effective projects, it is necessary to use methods of computer simulation of flooding risk of the territory. And for the effective implementation of a portfolio, it is necessary to prioritize projects in it according to a new ratio, which will include the security of territories [7].

A "Strategy for the development of the Lviv region for the period up to 2020" was developed according to the Resolution of the Cabinet of Ministers of Ukraine dated August 6, 2014 №385. It approves the "State Strategy for Regional Development for the Period till 2020" and the Decree of the President of Ukraine dated January 12, 2015 №5, "On the Strategy of Sustainable Development" Ukraine 2020". The document envisages strengthening of the safety of life of the inhabitants of the region by increasing the socioeconomic, natural and technogenic safety of the territories. In addition, in order to implement the provisions of Directive 2007/60 / EC of the European Parliament and of the Council of 23 October 2007 on the assessment and management of flood risks to the SES of Ukraine [8], the following tasks were assigned:

1. Formulate plans for civil protection of the state level in peacetime and in a special period, submit them to the Minister of Internal Affairs for submission to the Cabinet of Ministers of Ukraine in accordance with the established procedure, organize planning of civil protection measures by central and local executive authorities;

2. Implement measures for the implementation of engineering civil protection measures, provide initial information and requirements necessary for the development and planning of such measures upon request of customers;

3. Performs forecasting of the probability of occurrence of emergencies, defines the indicators of risk and regionalization of the territory of Ukraine regarding the risk of emergencies;

4. Keeps the state register, registers and stores of the hydrometeorological observations, maintains an information base for hydrometeorological data and data on the state of the environment; 
5. Provides forecasting of weather, hydrological regime of water objects, dangerous and natural hydrometeorological phenomena, productivity of agricultural crops;

6. Develop and submit to the Cabinet of Ministers of Ukraine, in accordance with established procedure, for consideration by the Minister of Internal Affairs proposals to increase the effectiveness of protection of the population and territories against emergencies, and improve the civil protection system in the respective territories.

The problems of the functioning of the SES of Ukraine prove the existing (reactive) organization of civil defence forces and protection measures from emergency need improvement. Therefore, it is impossible to perform all tasks assigned to the service without the use of a portfolio-oriented approach (proactive) to implement emergency protection projects. Particularly acute this is felt when performing tasks with the help of projects of different nature, different process components, but aimed at achieving one goal. Such projects usually form a portfolio of projects for more efficient management. One of such tasks is to ensure the safety of the population and territories from hydrometeorological emergencies, which achieve the realization of territories protection projects from flooding.

Today, modern portfolio management focuses on building a portfolio of value-based projects. The main concept of the value-added approach is to create a portfolio of projects with the maximum benefit. This approach involves ensuring that projects and programs included in the portfolio are reviewed in order to prioritize according to organizational values.

\section{Aim of the investigation}

Under the project of the territory, protected from flooding is understood as limited in time, resources and quality requirements a unique set of processes, aimed at creating civil engineering and engineering facilities to achieve social value - the safety of the population and territories.

The main features of such projects are:

1. Obtaining social value, and not financial benefits as a result of the project, due to the achievement of the minimum number dead, injured and material damage;

2. A limited period of time for the implementation of the project, which is conditioned by the uncertainty and spontaneity of the occurrence flooding;

3. A limited amount of financial and human resources, which is explained by the allocation a limited number of financial resources from the budget and the involvement of the staffing level;

4. The specific direction of the project's implementation for a specific purpose, which is due to the implementation of unique activities in a certain territory and limited to the implementation in another territory;

5. Implementation of the project in conditions of uncertainty associated with the sudden emergency.

\section{Practical results}

Realization of projects for protecting the territory from flooding in the form of a portfoliooriented (proactive) approach will enable to achieve the strategic goal of the SES of Ukraine - ensuring safe living conditions of the population and protecting the territories from emergencies due to limited resources.

Since the classic model of project portfolio management under the international PMI standard [6] is not appropriate in our case, then the existing portfolio management model needs to be developed or improved. 
Portfolio management is a set of interrelated business processes that simplify organizational and investment decisions. Portfolio components and management processes selected to obtain specific benefits (overall performance) in an organization. Therefore, the choice of portfolio management processes is a strategic decision $[9,10]$.

The project-oriented management allows to proactively projects managing of the SES of Ukraine, which require the implementation of measures to protect not only the elimination of the consequences of emergencies, but also to prevent the emergence of dangerous striking factors.

According to the National Report on the state of the technological and natural situation in Ukraine, for the year 2011, 13 meteorological emergencies were recorded, in 2012 this figure increased to 22. However, in 2013, the number of emergency hydrometeorological events decreased to 14 , which is due to an abnormally warm winter. However, further, the number of natural hydrometeorological situations is only increasing, for example, in 2014; there were 20 emergencies of this type, and in 2015, 26, which gives rise to anxiety.

The portfolio of flood protection projects is a set of protection projects united together for the effective management of the resources of the SES of Ukraine to achieve the strategic goal of ensuring the safety of the population and territories.

The formation of a portfolio projects for protecting territories from flooding is the application of knowledge, skills, tools and methods of forming a portfolio to meet the requirements, as well as specifically to the subprocess of modelling of catchment basins. Such an approach requires the efficient implementation of the subprocess of catchment basins modelling of the actualization phase of the portfolio protection projects from flooding and modelling of the risk areas of flooding of the territory and mathematical modelling of the height of flooding of the territory $[11,12]$.

According to the PMI standard, a group of processes for forming a portfolio of projects includes processes for identifying, categorizing, evaluating and selecting components, identifying portfolio risks, analyzing portfolio risks, prioritizing components, responding to portfolio risks, balancing a portfolio, establishing portfolio communication, and authorizing components [13-15].

In contrast to the classical model, the conceptual model for building a portfolio of projects for protecting territories from flooding includes the stages: updating, identification and selection, going as one whole, and prioritizing. Exclusion of categorization stages, appraisal of project applicants, and balancing of selected projects give the opportunity to accelerate the formation of a portfolio of projects and implement them as soon as possible.

For management that is more effective and further formation of a portfolio projects for protecting territories from flooding, we will introduce a process called the phase of updating of the portfolio projects for protecting the territory from flooding, which includes subprocess of modelling of catchment basins. This stage will determine the main natural hazards and necessary territories for implementation of a complex measures for protection territories from flooding based on the general indicator «danger level of territories» by defining a generalized criterion of priority territories for the implementation of a portfolio projects and the formation of a ranged table for selecting the most vulnerable territory. This method will be simpler than existing methods and can be applied not only for emergency response.

In the modern world, the system of monitoring and forecasting of emergencies becomes on the first place in the fight against man-made disasters and natural disasters. The perspective of this direction is obvious. In the area of population protection and territories, monitoring and forecasting of emergencies plays an important role. Since monitoring, analysis, assessment of the state and changes in the identified potential sources of emergencies, as well as a forecast of the impact on the safety of the population, organizations, the environment will allow the development and implementation of measures 
aimed at for prevention and liquidation of emergencies, minimization of socio-economic and environmental consequences [16].

The results of monitoring and forecasting of the National Assembly may become one of the defining criteria when making managerial decisions in the activities of civil protection bodies and units. Accurate and prompt information on a dangerous natural phenomenon, an accident or a dangerous technological event, etc., reflects the probability of occurrence and development of an emergency on the basis analysis of possible causes its occurrence. Sources in the past and present will allow qualitatively and effectively to develop programs and plans, take effective decisions on the prevention and elimination of emergencies.

SES of Ukraine carries out a number of tasks to be in parallel with the costs of the same resources (financial, human, and time). Therefore, for effective functioning, as well as in connection with the extremely fast pace of development of society and the increase in number of emergencies, the SNS of Ukraine needs to use portfolio management in its activities [1]. This is understood by the heads of the service and introduces appropriate reforms, as stated in the Resolution of the Cabinet of Ministers of Ukraine dated January 25, 2017 № 61-p "On Approving the Strategy for Reforming the State Emergencies Service of Ukraine".

As portfolio management is only evolving, it requires the development of new models and methods for managing portfolios applied to the respective tasks, tasks and areas of activity.

The sections of the work provide an implementation of the developed method of updating the portfolios projects of protection of territories from flooding based on the overall assessment of the "level security of territories" and the model of identification. Selection projects for protecting the territory from flooding based on the assessment of the territory according to the criteria of the height flooding and the rationality protection systems are the decision of the tasks of the SES of Ukraine for such an important task as protecting the population from flooding. The result of these processes is a portfolio of projects to protect the territory from flooding.

However, portfolio-oriented management is not only in the formation of a portfolio, but also in its efficient management. Therefore, a conceptual model for forming a portfolio of projects for protecting the territory from flooding, presented as a scheme, is developed (Figure). 


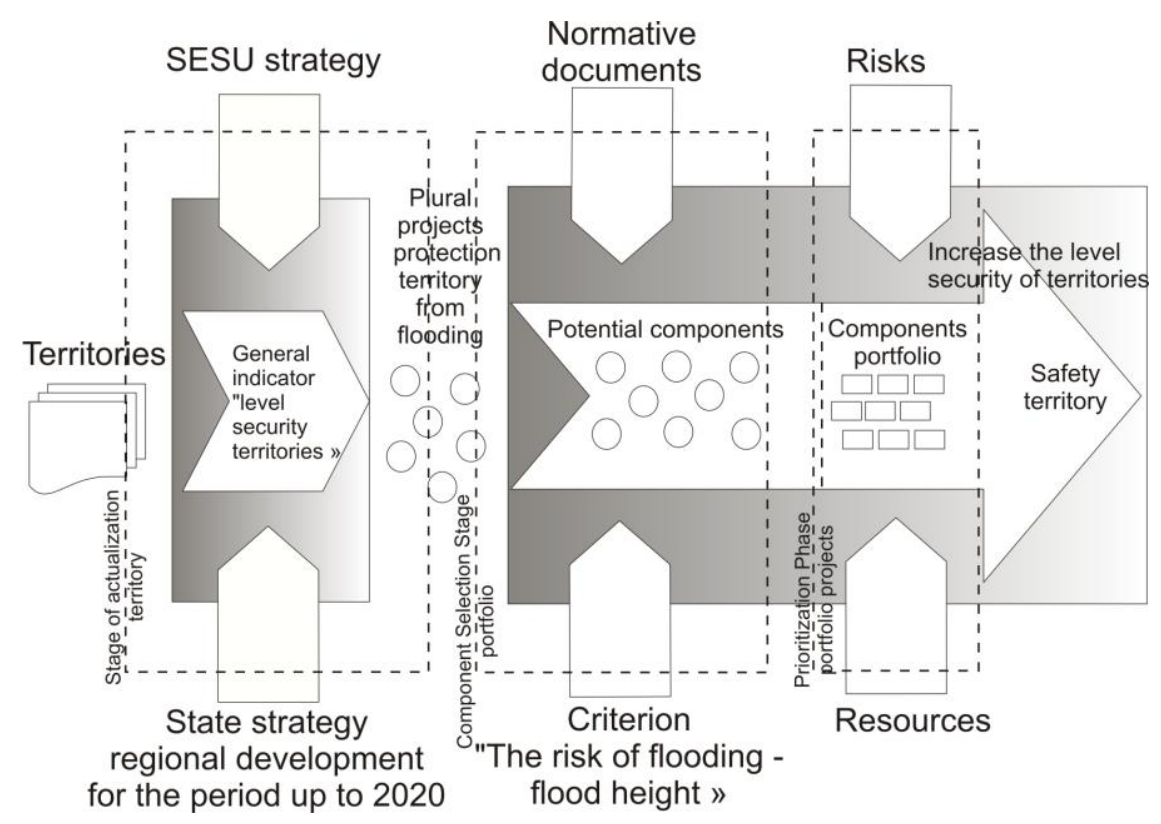

Fig. 1. Conceptual model for building a portfolio of projects protecting the territory from flooding for the State Emergency Service of Ukraine (SESU).

\section{Theoretical results}

According to the model, the main goal of the global project to form a portfolio of protection projects against flooding is to ensure the safety of territories and the vital functions of the population on them. The model envisages the implementation of the phase updating of the territories projects protection from flooding based on the assessment of the overall indicator "danger level of territories", which is intended to determine the priority for the implementation of the portfolio of the territory in terms of security. This method involves the selection of safety criteria and expert assessments of the territory according to selected criteria. The method is influenced by the strategy of the SES of Ukraine and the regional strategy for the development of the administrative territory.

After selecting the most important areas of protection there is a stage of identification and selection of potential components of the portfolio, which consists in selecting the applicants based on the assessment of the territory according to the criteria "flood height the risk of flooding" and "rationality implementation of security systems." This stage is influenced by the current normative documents of Ukraine and international standards.

Further, the portfolio components prioritized take into account the necessary expenses for the implementation of alternative sets of these projects and available financial resources, which provides an opportunity to receive a set of assessments of the portfolio projects and to determine the priority of the projects [2].

The presented conceptual model is aimed at raising the level safety of territories and vital functions of the population, which is the main task of the leadership for the SES of Ukraine. 


\section{Conclusions}

In this article, an improved conceptual model of the project portfolio formation is proposed that includes a new phase of updating portfolio projects for protecting the territory from flooding, which in turn includes processes for calculating the generalized indicator of the relevance of territories and modelling of catchment processes. This make possible selecting hazardous territories for the formation of portfolios projects to protect territories from flooding and improving the stage of project portfolio formation in the applied emergency protection area.

\section{References}

1. A. Havrys, Project management in the development of society. KNUBA, 76 (2016) (in Ukrainian)

2. O. Medvedieva, Project management and production development 2(34), 122 (2010) (in Ukrainian)

3. Project management institute. Annual report 2013. Access: https://www.pmi.org//media/pmi/documents/public/pdf/about/annual-reports/pmi-annual-reportconsolidated-financials-2013.pdf.

4. J. Gustaffson, A. Salo. Operations Res. 53/6 (2005)

5. R.G. Cooper, S.J. Edget, E.J. Kleinschmidt. Research-Technology Management 43/2, 29 (2000)

6. The Standard for Portfolio management. Project Management Institute, 203 (2008).

7. Living with Risk. A global review of disaster reduction initiatives: ADRC, ISDR, UN, WMO, 384 p. (2002)

8. The Decree of the Cabinet of Ministers of Ukraine dated December 16, 2015, №1052

"On Approval of the Regulation on the State Service of Ukraine for Emergencies" (in Ukrainian)

9. Y. Teslia, T. Latysheva, East Europ. Magazine of Adv. Techn. 1(3), 12 (2016) (in Ukrainian)

10. Y. Teslia, V. Kotetunov, Business Inform. 3, 92 (2015). (in Ukrainian)

11. Guide to the Project Management Body of Knowledge (PM BOOK). Project Management Institute, 586 (2013)

12. Y. Starodub, A. Havrys, Visnuk LSU LS J. 13, 70 (2016). (in Ukrainian)

13. I. Fedotova, Economy of the transport complex 27, 88 (2016) (in Ukrainian)

14. N. Rulikova, Project management and production development 4(24), 73 (2007). (in Ukrainian)

15. O. Koliada, Project management and production development 1(33), 161 (2010) (in Ukrainian)

16. Y. Starodub, A. Havrys, Central Europ. J. Sci. Research 42 (2015) 